\title{
PENGENALAN BAHASA INGGRIS TEPAT GUNA BAGI SISWA-SISWI SD CIHUNI - TANGERANG
}

\author{
MV. Santi Hendrawati \\ Dosen Bahasa Inggris Universitas Multimedia Nusantara \\ e-Mail : santi@umn.ac.id
}

\begin{abstract}
ABSTRAK
Jarak tidak lagi menjadi kendala bagi individu- individu untuk mendapat informasi ataupun berinteraksi dengan individu lain di negara yang berbeda. Hanya saja, untuk bisa berkomunikasi dengan baik, lancar, tidak terjadi salah pengertian dibutuhkan kemampuan berkomunikasi dengan bahasa yang sama-sama bisa dipahami - bahasa yang universal. Bahasa universal yang dimaksud tersebut adalah bahasa Inggris. Sayangnya, menguasai dan fasih berbahasa Inggris bukan perkara sepele. Rasanya sulit bila bahasa Inggris yang secara umum sangat berbeda dari bahasa Indonesia untuk dikuasai dalam hitungan hari, dua tiga minggu, bahkan sebulan. Perbedaan kedua bahasa tersebut sangat besar - perbedaan dari sisi kaidah tatabahasa, pengucapan, maupun perbendaharaan kata. Dituntut cukup waktu, ketekunan, motivasi tinggi dan target pasti untuk memperolehnya. Diharapkan dengan mulai mempelajari bahasa Inggris dari SD, kelak lahir generasi muda Indonesia yang berkemampuan bahasa Inggris baik dan kelak mampu berkiprah di dunia internasional. Apalagi, sejak tahun 2015, Indonesia sudah menjadi salah satu negara Masyarakat Ekonomi Asia, yang jelas akan muncul kebutuhan ketersediaan tenaga kerja yang tidak hanya terampil bekerja di bidangnya, tetapi juga memiliki kemampuan berkomunikasi dalam bahasa Inggris yang baik. Dengan memiliki kemampuan bahasa Inggris yang baik, akan muncul rasa percaya diri tinggi; yang kemudian mendorong munculnya rasa diri mampu bersaing atau berdaya saing tinggi.

Melihat kendala sekaligus peluang ini, Universitas Multimedia Nusantara bekerja sama dengan SD Cihuni II Tangerang, berikhtiar mengadakan pembelajaran bahasa Inggris bagi peserta didik/ siswa SD II CIHUNI, Tangerang. Metode pengajaran Bahasa Inggris cukup banyak sebagaimana dilakukan di Cihuni untuk meningkatkan minat siswa/siswi belajar adalah metode Audio-Lingual. Dengan metode ini siswa/siswi diperkenalkan dengan beberapa kata kerja, kata sifat dan kata keterangan dalam satu kalimat. Siswa/siswi diminta mengulang-ulang kata-kata itu dalam bentuk lagu. Hasilnya , minat para pelajar SD dalam mempelajari Bahasa Inggris menjadi lebih tinggi, dan Bahasa Inggris menjadi salah satu pelajaran yang disukai siswa karena diberikan secara menarik dan tepat guna.
\end{abstract}

Keywords : Bahasa Inggris, Pelatihan Bahasa Inggris, metode audio lingual, daya saing siswa 


\section{PENDAHULUAN}

Amerika, negara adi daya, letaknya jauh dari Indonesia. Perlu belasan jam untuk terbang dari Jakarta menuju Los Angeles. Tetapi, apa pun yang terjadi di Amerika, dalam hitungan detik bisa diketahui warga Indonesia.

Jarak tidak lagi menjadi kendala bagi individu- individu untuk mendapat informasi ataupun berinteraksi dengan individu lain di negara yang berbeda. Hanya saja, untuk bisa berkomunikasi dengan baik, lancar, tidak terjadi salah pengertian dibutuhkan kemampuan berkomunikasi dengan bahasa yang sama-sama bisa dipahami - bahasa yang universal. Bahasa universal yang dimaksud tersebut adalah bahasa Inggris.

Sayangnya, menguasai dan fasih berbahasa Inggris bukan perkara sepele. Rasanya sulit bila bahasa Inggris yang secara umum sangat berbeda dari bahasa Indonesia untuk dikuasai dalam hitungan hari , dua tiga minggu, bahkan sebulan. Perbedaan kedua bahasa tersebut sangat besar - perbedaan dari sisi kaidah tatabahasa, pengucapan, maupun perbendaharaan kata. Dituntut cukup waktu, ketekunan, motivasi tinggi dan target pasti untuk memperolehnya.
Untuk mengantisipasi kendala ini, Pemerintah menganjurkan agar bahasa Inggris mulai diberikan kepada para peserta didik /siswa Sekolah Dasar (SD). Diharapkan dengan mulai mempelajari bahasa Inggris dari SD, kelak lahir generasi muda Indonesia yang berkemampuan bahasa Inggris baik dan kelak mampu berkiprah di dunia internasional. Apalagi, sejak tahun 2015, Indonesia sudah menjadi salah satu negara Masyarakat Ekonomi Asia, yang jelas akan muncul kebutuhan ketersediaan tenaga kerja yang tidak hanya terampil bekerja di bidangnya, tetapi juga memiliki kemampuan berkomunikasi dalam bahasa Inggris yang baik. Dengan memiliki kemampuan bahasa Inggris yang baik, akan muncul rasa percaya diri tinggi; yang kemudian mendorong munculnya rasa diri mampu bersaing atau berdaya saing tinggi.

Melihat kendala sekaligus peluang ini, Universitas Multimedia Nusantara bekerja sama dengan SD Cihuni II Tangerang, berikhtiar mengadakan pembelajaran bahasa Inggris bagi peserta didik/ siswa SD II CIHUNI, Tangerang.

Dari aktivitas mengenal dan belajar bahasa Inggris ini diharapkan akan terdeteksi 
kendala apa saja yang dihadapi guru maupun peserta didik dalam proses belajar/mengajar bahasa Inggris? Antara lain, metode belajar/mengajar manakah yang sesuai untuk siswa didik dengan status sosial kurang mampu? Materi pelajaran seperti apa yang mampu memotivasi peserta didik untuk belajar bahasa Inggris? Kompetensi apa saja yang harus dimiliki pendidik dalam menjalankan proses belajar/mengajar selain kompetensi akademis? Selain termotivasi untuk belajar bahasa Inggris, adakah peserta didik mendapat manfaat lainnya?

Program pembelajaran bahasa Inggris bahasa Inggris bagi peserta didik/siswa SD II Tangerang bernama "Mengembangkan Kepribadian Siswa Sejak Dini dengan Bahasa Inggris" yang merupakan kegiatan Pengabdian Kepada Masyarakat dari Universitas Multimedia Nusantara (LPPM UMN), diselenggarakan dalam rangka memperkenalkan dan menumbuhkembangkan minat siswa SD pada bahasa Inggris. Aktivitas ini diikuti siswa SD kelas dua (II A dan II B) SD CIHUNI, TANGERANG, diikuti sekitar 80an peserta didik.

\section{Analisis Situasi}

Maksud pengenalan dan aktivitas pembelajaran bahasa Inggris sejak dini ini diharapkan:

1. Para siswa SD makin mengenal dan menyukai bahasa Inggris, sebagai bahasa yang penting untuk dikuasai bagi kesuksesan masa depan mereka.

2. Para siswa SD mampu mengucapkan kata-kata bahasa Inggris dengan benar, terutama yang berkaitan dengan konsep benda. tempat, atmosfer/situasi komunikasi tertentu.

3. Para siswa SD mampu menyanyikan lagu-lagu bahasa Inggris dan melafalkan kata-katanya dengan benar dan fasih.

4. Para siswa SD menjadi lebih percaya diri dan makin menghargai bahasa Indonesia, lewat pengenalan bahasa dan budaya bahasa Inggris.

5. Para siswa SD terdorong untuk mampu memiliki daya saing tinggi, memiliki wawasan kehidupan manusia yang lebih luas.

Adapun tujuan aktivitas pembelajaran pengenalan bahasa Inggris adalah:

Pendidikan 
1. Ditemukan materi-materi yag sesuai dengan kebutuhan siswa SD, terutama sesuai dengan budaya dan tatakrama kehidupan Indonesia.

2. Ditemukan metode pengajaran dan pendekatan belajar-mengajar bahasa Inggris bagi siswa SD di Indonesia/

3. Ditemukan kendala-kendala proses belajar-mengajar bahasa Inggris kepada siswa-siswi SD untuk kemudian dicarikan solusinya.

4. Dibangun rasa suka dan minat untuk menguasai bahasa Inggris yang sangat bermanfaat bagi masa depan mereka.

5. Didapat kesempatan untuk memproduksi materi pelajaran bahasa Inggris bagi siswa-siswi SD yang sesuai dengan kebutuhan peserta didik oleh dosen dan mahasiswa UMN, baik dalam bentuk cetak maupun digital.

\section{Kerangka Konseptual}

anak dapat menguasai bahasa tanpa susah payah. Bahkan, di beberapa negara, seorang siswa/siswi dapat menguasai dua atau tiga bahasa sekaligus. Bila satu keluarga terpaksa harus pindah ke negara lain, anak-anak yang ikut pindah, tampaknya mampu 'memungut' bahasa di lingkungannya yang baru dengan mudah. Dengan kata lain, mereka dapat mengadopsi bahasa barunya tanpa repot memikirkan tatabahasa atau perbendaharaan kata, atau cemas memikirkan potongan kata apa yang harus dipakai untuk mengungkapkan gagasannya.

Stephen Krashen, seorang pakar bahasa (1982) menyatakan bahwa anak-anak menguasai bahasa dengan alam bawah sadar dan tanpa beban. Oleh karena itu, perlu dipertimbangkan metode yang tepat dan proses belajar yang menarik bagi anak-anak.

Salah satu metode di antaranya adalah TPR - Total Physical Response - dibutuhkan Pendidikan 1000 
dan diterapkan agar siswa/siswi sungguh terlibat dalam proses belajar mengajar. Umpamanya, ketika menyebut angka 8 (delapan) ... guru tidak sekadar menyebut angka, tetapi juga membahasakannya dengan gerak tubuh - seperti ular yang menggeliat hahaha- yang membuat siswa/siswi tertawa lucu tetapi membantu mereka mengingat gerakan tubuh sekaligus hafal dengan angkanya. Dan setiap kali melihat guru menggeliar seperti ular - siswa/siswi ingat itu adalah gerakan yang mengacu pada angka 8 (delapan).

Metode pengajaran bahasa lainnya untuk meningkatkan minat siswa/siswi belajar adalah metode Audio-Lingual. Dengan metode ini siswa/siswi diperkenalkan dengan beberapa kata kerja, kata sifat dan kata keterangan dalam satu kalimat. Siswa/siswi diminta mengulangulang kata-kata itu dalam bentuk lagu: If you.re happy .... clap your hands .... plok plok plok! Sambil bernyanyi, siswa/siswi belajar mengenal kata sifat: senang (happy), kata kerja dalam bentuk lagu: bertepuk tangan (clap your hands), menjejakkan kaki (stamp your feet), atau menunjuk hidung (point your nose). Dengan pengulangan kata, frasa ataupun clausa, diharapkan siswa/siswi terbantu untuk mengingat perbendaharaan katanya (Brown, 2001:42-43; Richard, 2006).

Lev Vygotsky, seorang psikolog asal Rusia,1836-1934), menyatakan bahwa bermain-main adalah bagian penting dalam dunia anak; lewat permainan anak-anak berkesempatan mengembangkan kemampuan berbahasa sekaligus belajar memahami dunia luar. Siapa pun menerima dan paham bila dikatakan dunia anak-anak adalah dunia bermain. Dunia yang penuh dengan gerak, gelak tawa dan permainan. Makanya, bila kegiatan belajar menjadi kegiatan yang penuh dengan permainan, Pendidikan 1001 
perlombaan, dan kegembiraan, di saat itulah anak akan tergerak, termotivasi untuk ikut serta dalam kegiatan yang menggembirakan dan memberikan yang terbaik bagi dirinya.

Berangkat dari dasar pemikiran seperti itu, proses pengenalan bahasa Inggris untuk siswa-siswi SD Cihuni ini di sampaikan dalam aneka macam permainan, perlombaan dalam bentuk tebak tepat. Bentuk pembelajaran ini tidak hanya membuat siswa/siswi merasa senang dengan mencoba menjawab pertanyaan tentang kata-kata baru dalam bahasa Inggris yang mereka dapat, tetapi mereka pun berkesempatan untuk memamerkan keterampilan baru dalam berbahasa kepada teman bermain di rumah ataupun kepada orang tua atau anggota keluarga di rumah. Sekaligus, dalam proses belajar seperti ini, siswa/siswi mendapat pelatihan membangun daya saing dalam diri mereka dengan teman-teman sekelas secara sehat.
Begitu pula dengan metode 'role play', para siswa/siswi merasa diberi kesempatan untuk mengembangkan, menggali dan mengungkapkan imajinasi mereka dalam aktivitas nyata. Menurut Vygotsky, dengan berkesempatan berinteraksi secara sosial, anak-anak mendapat kesempatan dasar untuk mengembangkan daya kognitif mereka.

\section{Pemanfaatan Lagu-lagu}

Lagu bisa digunakan untuk memperkenalkan topik materi pengajaran. Sewaktu menyanyi dan bergembira, siswa/siswi tidak sekadar bersenang-senang tetapi juga mudah mengingat kata-kata yang diajarkan. Lagu menjadi alat bantu andal untuk memotivasi siswa-siswi menambah perbendaharaan kata-kata.

\section{Lagu-lag digunakan dalam kelas} pemula ini adalah lagu-lagu yang cenderung repetitif dan memiliki ritme yang kuat. Lagu- 
lagu ini disukai dan cepat dikuasai anak-

anak. Lirik lagu dipilih dengan kata-kata yang punya konteks, baik dari segi struktur maupun perbendaharaan katanya.

Selain membuat hati siswa-siswi bersemangat, bergembira, lagu-lagu yang dipilih, bertujuan membangun rasa percaya diri pada siswa/siswi, sehingga siswa/siswi yang pemalu sekalipun tergerak untuk ikut bernyanyi. Di samping itu, lagu-lagu ini juga dapat dimanfaatkan sebagai cara/alat untuk membangun identitas diri siswa/siswi sebagai anggota dari kelas. Siswa/siswi kerap merasa bangga bila ditanya di rumah oleh orang tua apa yang sudah mereka pelajari di sekolah dan dengan bangga 'memamerkan ' apa yang telah pelajari bersama teman sekolah. Banyak lagu yang membantu pengembangan ingatan dan konsentrasi anak, serta koordinasi fisik, terutama lagu-lagu yang bisa didramatisir atau bisa ditarikan. Bagi guru, lagu-lagu merupakan cara paling menarik untuk memperkenalan satu topik dan bisa disesuaikan dengan topik, keterampilan, bahasa dan kegiatan lintas bahasa. Oleh karena itu perlu mempertimbangkan pilihan lagu-lagu yang akan dipakai di dalam kelas, antara lain: Untuk memperkenalkan topik tatabahasa.

Sebagian lagu dengan sendirinya memerkenalkan pengajaran dan pemahaman tatabahasa. Materi ini bisa dintegerasikan dengan pelajaran tatabahasa tertentu.terutama di kelas pmeula, saat siswa masih belajar pola tatabahasa yang sedernana, lagu berperan penting sebagai langkah awal pengenalan bahasa Inggris.

Dari hasil beberapa penelitian penguasaan bahasa menunjukkan bahwa kata-kata leksikal perlu diulang beberapa kali sebelum diinternalisasi oleh si siswa. Lagu 
bisa dijadikan sebagai alat untuk mengulang dan menghayati kata dan cocok untuk anakanak dengan berbagai keterampilan. Misalnya, lagu "Clap your hands" .."Stamp your feet" mengajak siswa untuk mengulang kata-kata yang sederhana dan memperkenalkan kata kerja yang dapat didramatisir oleh siswa/siswi.

Lagu juga bisa disesuaikan dengan tema aktivitas. Topik tentang binatang, bisa digunakan dalam hal ini antara lain 'Old Macdonal had a farm' Selain itu lagu bisa mengembangkan keterampilan mendengar

Variasi lagu beranek struktur dan perbendaharaan kata yang cocok untuk mengembangkan keterampilan mendengarkan. Misalnya lagu: Ten Little Indian” yang bercerita tentang anak Indian, hutan dan kegiatan hitung menghitung dan lingkungan seara umum. Lagu ini disukai anak-anak karena bisa didramatisasikan.
Sekaligus mengembangkan daya imajinasi siswa-siswa yang suka bergerak dan enerjik.

\section{METODE PELAKSANAAN}

Siswa/siswi SD kelas dua yang berusia 6-8 tahun termasuk dalam kategori siswa yang masih suka bermain-main. Oleh karena itu, suasana kelas dalam program pengenalan bahasa Inggris ini pun dibuat sesantai mungkin, terdiri dari banyak permainan, banyak menyanyi dan menari. Untuk mencipta suasana belajar yang menyenangkan seperti itu, metode pembelajaran pun diatur dan dibuat menyenangkan (Brown, 2001: 42-51), dalam bentuk: Story telling,Audio lingual, Direct Approach, Role play,Singing and dancing. Dengan metode Audio Lingua; ini siswa/siswi diperkenalkan dengan beberapa kata kerja, kata sifat dan kata keterangan dalam satu kalimat. Siswa/siswi diminta mengulang-ulang kata-kata itu dalam bentuk Pendidikan 1004 
lagu: If you.re happy .... clap your hands ....

plok plok plok! Sambil bernyanyi, siswa/siswi belajar mengenal kata sifat: senang (happy), kata kerja dalam bentuk lagu: bertepuk tangan (clap your hands), menjejakkan kaki (stamp your feet), atau menunjuk hidung (point your nose). Dengan pengulangan kata, frasa ataupun clausa, diharapkan siswa/siswi terbantu untuk mengingat perbendaharaan katanya (Brown, 2001:42-43; Richard, 2006).

\section{PELAKSANAAN KEGIATAN}

Pelaksanaan kegiatan dilakukan selama satu semester dan dibina oleh dosendosen Bahasa Inggris dari Universitas Multimedia Nusantara dengan didampingi oleh sejumlah mahasiswa UMN pada 5 Agustus 2016 - 5 Desember 2016.

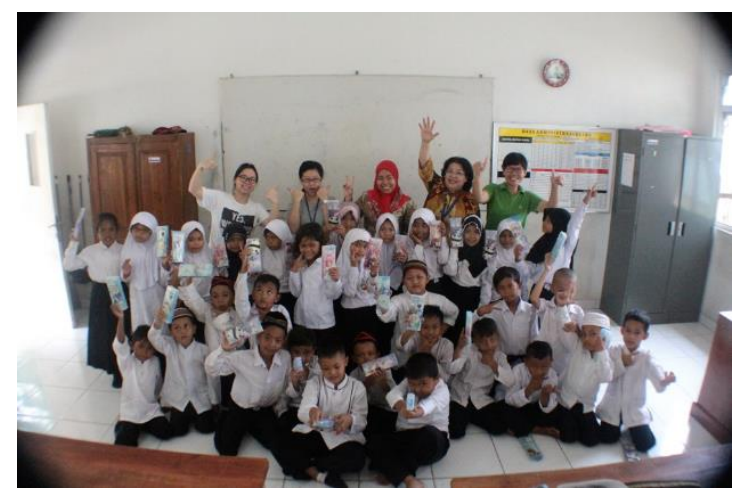

\begin{tabular}{|c|c|c|}
\hline $\begin{array}{l}\text { Subject: } \\
\text { English }\end{array}$ & $\begin{array}{l}\text { Goal: } \\
\text { - SS understand simple instruction in } \\
\text { English } \\
\text { - SS understand alphabetical order and } \\
\text { numbering sequence in the target } \\
\text { language }\end{array}$ & Date: $05 / 08 / 2016$ \\
\hline $\begin{array}{l}\text { Previous } \\
\text { Greetings }\end{array}$ & $\begin{array}{l}\text { Ice breaker } \\
\text { Singing 'A,B.C and } 1.2,3 \text { ' song } 15 \text { ', }\end{array}$ & $\begin{array}{l}\text { Media } \\
\text { Daily activities flash cards }\end{array}$ \\
\hline \multirow{3}{*}{$\begin{array}{l}\text { Tools: } \\
\text { Teacher's } \\
\text { props and } \\
\text { realia }\end{array}$} & Method: & \multirow{2}{*}{$\begin{array}{l}\text { Hands on Materials } \\
\text { - Printable worksheet of alphabetical } \\
\text { order and numbering sequence } \\
\text { - Printable worksheet of identifying long } \\
\text { a and short a }\end{array}$} \\
\hline & $\begin{array}{l}\text { Learning Activities: } \\
\text { - SS are asked to sing a song and identify } \\
\text { the alphabetical order } 10^{\circ} \\
\text { - SS are esked to sing a song and identify } \\
\text { the numbering sequence of } 1-1010^{\circ} \\
\text {. SS do analytical and memory games } 10^{\circ}\end{array}$ & \\
\hline & $\begin{array}{l}\text { Assessment } \\
\text { Oral: Sing a song } \\
\text { Written: - Printable worksheet of } \\
\text { alphabetical order and numbering sequence } \\
\text { - Printable worksheet of identifying long a } \\
\text { and short a } 15^{\prime}\end{array}$ & $\begin{array}{l}\text { Reflection } \\
\text { Put on your thinking cap: What do you } \\
\text { learn today? Cut and paste } A B C \text { from } \\
\text { recycled magazine/newsletter } 10^{\circ}\end{array}$ \\
\hline
\end{tabular}

\begin{tabular}{|c|c|c|}
\hline $\begin{array}{l}\text { Subject: } \\
\text { English }\end{array}$ & $\begin{array}{l}\text { Goal: } \\
\text { - SS understand simple instruction in } \\
\text { English } \\
\text { - SS understand alphabetical order and } \\
\text { numbering sequence in the target } \\
\text { language }\end{array}$ & Date: $12 / 08 / 2016$ \\
\hline $\begin{array}{l}\text { Previous } \\
\text { Greetings }\end{array}$ & $\begin{array}{l}\text { Ice breaker } \\
\text { Singing 'A,B,C and } 1,2,3 \text { ' song } 15^{\prime}\end{array}$ & $\begin{array}{l}\text { Media } \\
\text { Daily activities flash cards }\end{array}$ \\
\hline \multirow{3}{*}{$\begin{array}{l}\text { Tools: } \\
\text { Teacher's } \\
\text { props and } \\
\text { realia }\end{array}$} & $\begin{array}{l}\text { Method: } \\
\text { Audio lingual suggestopedia and CLT }\end{array}$ & \multirow{2}{*}{$\begin{array}{l}\text { Hands on Materials } \\
\text { - Printable worksheet of alphabetical } \\
\text { order and numbering sequence } \\
\text { - Printable worksheet of identifying long } \\
\text { a and short a }\end{array}$} \\
\hline & $\begin{array}{l}\text { - Audro lingual, suggestopedia and CLT } \\
\text { Learning Activities: } \\
\text { - SS are asked to sing a song and identify } \\
\text { the alphabetical order } 10^{\circ} \\
\text { SS are asked to sing a song and identify } \\
\text { the numbering sequence of } 1-1010^{\circ} \\
\text { - SS do analytical and memory games } 10^{\circ}\end{array}$ & \\
\hline & $\begin{array}{l}\text { Assessment } \\
\text { Oral: Sing a song } \\
\text { Written: - Printable worksheet of } \\
\text { alphabetical order and numbering sequence } \\
\text { - Printable worksheet of identifying long a } \\
\text { and short a } 15 \text { ' }\end{array}$ & $\begin{array}{l}\text { Reflection } \\
\text { Put on your thinking cap: What do you } \\
\text { learn today? Cut and paste } A B C \text { from } \\
\text { recycled magazine/newsletter } 10^{\circ}\end{array}$ \\
\hline
\end{tabular}




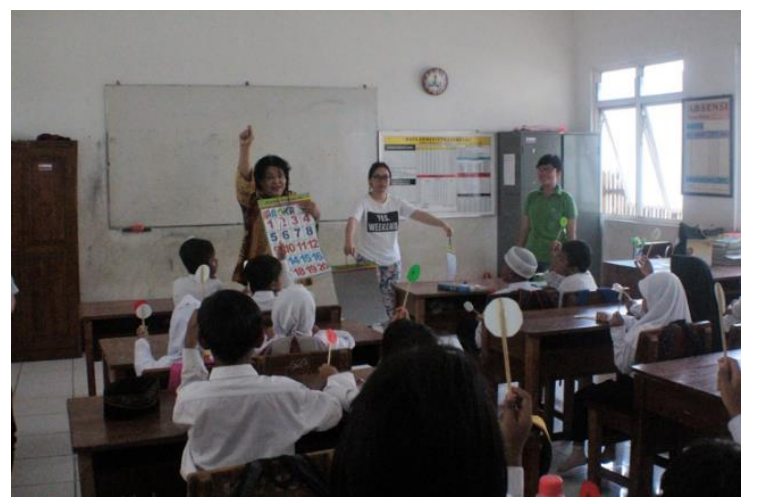

Atmosfer kelas yang rileks, penuh canda-tawa, tanpa tekanan/kewajiban, adalah kelas yang kondusif bagi siswa-siswi SD untuk belajar bahasa asing (baca: Inggris) Salah satu medium yang dipakai untuk menciptakan atmosfer seperti itu adalah lewat kegiatan menyanyikan lagu-lagu. Lagu adalah medium sederhana tetapi ampuh untuk memotivasi siswa-siswi belajar dan mengenal kata-kata, angka dan melatih pengucapan. Dengan menyanyi, siswa-siswi merasa rileks tetapi bersemangat belajar.

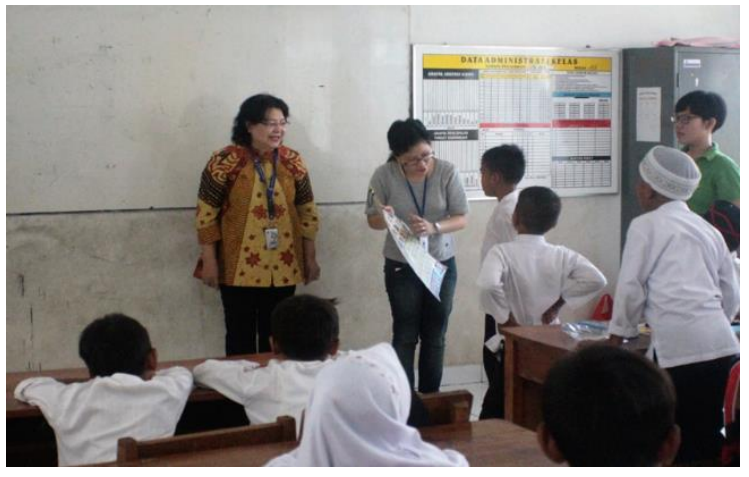

\section{KESIMPULAN DAN SARAN}

Meski siswa merasa senang dan tertarik dalam proses pembelajaran bahas Inggris tetapi perlu diperhatikan beberapa hal dalam menyanyi bersama siswa-siswi untuk mendapat capaian yang maksimal, antara lain:

1. Sebaiknya disiapkan beberapa masukan sebelum mulai menyanyi. Misalnya, menulis kata-kata/lirik lagu di papan tulis sebelum mulai menyanyi. Siswa/siswi latihan mengucapkan/ melafalkan katakatanya sebelum menyanyi; atau bisa juga menggunakan realia. Misal, lagu 
"Old MacDonal had a Farm:

digunakan untuk latihan mengenal binatang dengan memakai flashcard. Atau lagu "The Alphabeth" dengan gambar buah-buahan atau sayursayuran.

2. Lirik lagu sebaiknya dipilih yang sederhana dan mudah dinyanyikan berulang-ulang. Bagi siswa pemula, lagu "The Alphabet song" adalah lirik lagu yang bisa digunakan untuk mengajak siswa/siswi belajar tentang alfabet.

3. Menerapkan gerakan tubuh - Total Physical Response (TPR) - saat menyanyi.

4. Sebaiknya dipilih lirik lagu denga kata-kata tunggal supaya mudah diingat siswa/siswi.

Di samping memanfaatkan lagu-lagu untuk menciptakan kelas yang kondusif untuk belajar, bermain peran, metode belajar dengan ALM, TPR, Direct Approach mampu memotivasi siswa/siswi untuk menguasai bahasa Inggris. Tanpa kewajiban menghapal aturan-aturan kaidah tatabahasa yang rumit, siswa-siswi merasa sudah 'bisa' berbahasa Inggris secara sederhana. Belajar bahasa Inggris menjadi kegiatan yang seru plus menyenangkan hati.

\section{DAFTAR PUSTAKA}

Brown, H. Douglas. 2001.Teaching by Principles: An Interactive Approach to Language Pedagogy. Second Edition. New York: Pearson Education Company.

Cameron, L. 2001. Teaching Language to Young Learners. Cambridge: Cambridge University Press

Harmer, Jeremy. 2007. How to Teach English. Edinburgh Gate. Essex: Person Education Limited.

Harmer, Jeremy. 2012. Teacher Knowledge. Edinburgh Gate. Essex: Pearson Education Limited.

Krashen, S.D. 1982. Principles and Practice in Second Language Acquisition. Oxford: Pergamon

Richards, Jack C. 2006. Communicative Language Teaching. Cambridge: Cambridge University Press. 